\title{
Ateroma arteri karotis pada radiograf panoramik sebagai diagnosis awal aterosklerosis
}

\author{
Dwi Putri Wulansari ${ }^{*}$, Farina Pramanik ${ }^{2}$
}

\begin{abstract}
Objectives: This review aimed to understand the radiographic features of carotid artery atheroma on panoramic radiographs as an early diagnosis of atherosclerosis.
\end{abstract}

Literature Review: Carotid artery calcification is caused by a plaque known as an atheroma. Atheroma is a plaque composed of lipids and rich in calcium. If atheroma formation in the carotid arteries increases, it would cause stenosis of the blood vessels and increase the risk of stroke. On

panoramic radiographs, carotid artery atheroma appears as a heterogeneous radiopaque image with an irregular shape and well-defined borders. Radiopaque image located inferior to the angle of the mandible, close to the cervical spine (C3-C5) and above the hyoid bone.

Conclusion: Incidental findings on panoramic radiograph could be an initial reference for further examination and evaluation of atherosclerosis.

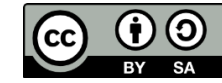

This work is licensed under eative Commons Attribution 4.0 which permits use, distribution and reproduction, provided that the original work is properly cited, the use is non-commercial and no modifications of adaptations are made.
${ }^{1}$ PPDGS Radiologi Kedokteran Gigi, Fakultas Kedokteran Gigi, Universitas Padjadjaran, Bandung, Indonesia, 40132

${ }^{2}$ Departemen Radiologi Kedokteran Gigi, Fakultas Kedokteran Gigi, Universitas Padjadjaran, Bandung, Indonesia, 40132

${ }^{*}$ Correspondence to:

Gunawan

凶dwi20008@mail.unpad.ac.id

Received on: August 2020 Revised on: September 2020 Accepted on: November 2020

Keywords: Atherosclerosis, panoramic radiograph, carotid artery atheromas

Cite this article: Wulansari DP, Pramanik F. Ateroma arteri karotis pada radiograf panoramik sebagai diagnosis awal aterosklerosis. Jurnal Radiologi Dentomaksilofasial Indonesia 2020;4(3)101-4. https://doi.org/10.32793/jrdi.v4i3.613

\section{PENDAHULUAN}

Aterosklerosis berasal dari Bahasa Yunani, Athero yang berarti bubur. Aterosklerosis merupakan istilah untuk menggambarkan hubungan antara degenerasi lemak dan kekakuan pembuluh. ${ }^{1} \quad$ Aterosklerosis adalah penyakit vaskulatur arteri yang ditandai dengan gangguan keseimbangan dan akumulasi abnormal dari lipid, sel-sel inflamasi, endapan matriks dan proliferasi sel otot halus pada dinding arteri, terutama arteri dengan ukuran medium dan besar. ${ }^{1,2}$ Adanya inflamasi kronik pada dinding arteri akan menyebabkan dinding arteri mengalami penebalan, penyempitan yang tidak/dapat disertai dengan kehilangan elastisitas dinding arteri. ${ }^{3,4}$

Banyak hal yang dapat menjadi etiologi asalusul dari aterosklerosis, namun berbagai etiologi tersebut akan melibatkan suatu fenomena biokimia yang menciptakan kalsifikasi patologis pada arteri, yang disebut sebagai ateroma. Ateroma merupakan suatu plak terkalsifikasi yang tersusun atas lipid dan fibroblas yang mengalami proliferasi. ${ }^{3,5}$ Ateroma sering ditemukan pada area bifurkasi arteri karotis dimana kecepatan aliran darah berkurang sehingga meningkatkan paparan partikel aterogenik yang rentan terhadap kalsifikasi. ${ }^{2,3}$ Jika arteri karotis dipengaruhi oleh ateroma, akan terjadi stenosis pada lumen pembuluh yang dapat meningkatkan resiko terjadinya stroke karena suplai darah ke otak berkurang. ${ }^{4,6}$

Aterosklerosis menjadi penyebab umum morbiditas dan mortalitas pada populasi di negara- negara maju dan prevalensinya meningkat di negara-negara berkembang., ${ }^{2,8}$ Dalam banyak kasus, aterosklerosis berkaitan dengan beberapa faktor resiko seperti penyakit kardiovaskular, riwayat stroke, hipertensi, diabetes melitus, hiperkolesterolemia, perokok, konsumsi alcohol, dan obesitas. ${ }^{6,8,9}$ Gejala awal aterosklerosis sangat sulit untuk dideteksi sehingga umumnya gejala akan terlihat pada saat pembuluh darah hampir sepenuhnya tersumbat oleh ateroma sehingga sangat berpotensi menyebabkan kematian. ${ }^{4,10-12}$ Hal inilah yang menjadi dasar perlunya deteksi awal dari pembentukan ateroma agar resiko terjadinya aterosklerosis dapat diminimalkan. 4,6,13 Dokter gigi, dalam hal ini ahli radiologi kedokteran gigi memegang peranan penting dalam mendeteksi tanda awal pembentukan ateroma melalui temuan insidental pada radiograf panoramik. ${ }^{3,6,14}$ Tujuan dari tinjauan literatur ini adalah untuk mempelajari gambaran radiografis ateroma arteri karotis pada radiografi panoramik sebagai diagnosis awal aterosklerosis.

\section{STUDI PUSTAKA}

\section{ETIOPATIOGENESIS}

Aterosklerosis adalah penyakit inflamasi kronis yang diawali dengan injury pada endotelium, yaitu lapisan sel yang membentuk barisan pembuluh darah. Cedera endothelial dapat berbentuk gaya 
mekanis, seperti tekanan darah tinggi yang dapat terjadi pada bifurkasi pembuluh darah; kondisi metabolik, seperti diabetes mellitus, yang memproduksi bahan-bahan yang secara langsung mencederai endothelium; atau agen dari lingkungan, seperti asap rokok atau agen infeksius, yang juga merusak fungsi sel endothelial. Cedera ini lalu mengakumulasi kolesterol lipoprotein berdensitas rendah (LDL) pada dinding pembuluh darah dan membentuk suatu garis berlemak. ${ }^{2}$

Pembentukan garis lemak yang merupakan akumulasi lipid ini terjadi pada lapisan intimal arteri. ${ }^{2}$ Retensi lipid merupakan langkah awal dalam pathogenesis aterosklerosis yang kemudian diikuti oleh inflamasi kronik pada area dinding arteri yang mengalami pembentukan garis-garis lemak dan kemudian membentuk jaringan fibrous. Garis-garis lemak berevlolusi membentuk ateroma yang terdiri atas tiga komponen, yaitu sel inflamasi, sel otot halus, komponen fibrous jaringan ikat dan komponen lemak lipid. Aterosklerosis memiliki perkembangan yang progresif yaitu pembentukan garis lemak selama 11-12 tahun dan pembentukan ateroma $15-30$ tahun. $^{1}$

\section{GAMBARAN ATEROMA ARTERI KAROTIS PADA RADIOGRAF PANORAMIK}

Ateroma pada arteri karotis merupakan suatu plak terkalsifikasi yang dapat diamati pada radiograf panoramik. Radiograf panoramik merupakan salah satu pemeriksaan pencitraan ekstraoral yang paling sering digunakan dalam kedokteran gigi karena merupakan evaluasi awal yang dapat memberikan informasi mengenai kondisi rahang secara keseluruhan dan dapat membantu dalam menentukan kebutuhan proyeksi selanjutnya untuk melihat lesi secara lebih mendetail. ${ }^{6,15}$

Pada radiograf panoramik, ateroma tampak sebagai gambaran nodular radiopak heterogen yang irregular pada jaringan lunak leher, dapat berupa lesi tunggal ataupun jamak dengan berbagai ukuran., ${ }^{6,11,14}$ Ateroma dapat tampak sebagai gambaran lesi yang unilateral maupun bilateral, dekat dengan tulang hyoid, epiglottis, dan cervical vertebrae. Dapat berlokasi di atas, di bawah atau di antara intervertebral discs $\mathrm{C} 3$ dan $\mathrm{C} 4$ dengan sudut $45^{\circ}$ terhadap angulus mandibula, $1.5 \mathrm{~cm}$ ke arah inferior dan $2.5 \mathrm{~cm}$ ke arah posterior angulus mandibula. ${ }^{7,9,12,14}$ Lokasi ateroma arteri karotis dapat dilihat pada beberapa radiograf panoramik berikut (Gambar 2,3).

\section{DISKUSI}

Radiografi panoramik merupakan suatu metode radiografi dengan dosis radiasi yang relatif rendah dan sederhana dalam pelaksanaan teknis pemeriksaannya sehingga sering digunakan di bidang Kedokteran Gigi untuk mengidentifikasi struktur anatomi di sekitar regio oral dan maksilofasial. Hal ini tidak jarang memberikan kesempatan kepada dokter gigi untuk mendeteksi pembentukan ateroma pada arteri karotis secara insidental namun dapat memberikan informasi yang penting dalam diagnosis dini ateroskelrosis. Berbagai penelitian terkait deteksi ateroma arteri karotis sebagai deteksi dini aterosklerosis telah banyak dilakukan. Namun ada beberapa hal yang perlu menjadi perhatian dokter gigi sebelum menentukan bahwa apakah yang terlihat pada radiograf panoramik itu merupakan ateroma pada arteri karotis. Beberapa anatomi radiopak dan kondisi patologis yang radiopak harus menjadi pertimbangan utama sebelum menegakkan suspek radiodiagnosis (Tabel. 1). 5,6,9,15,16

Pada saat dokter gigi mencurigai suatu gambaran radiopasitas pada radiograf panoramik sebagai ateroma pada arteri karotis, dokter gigi harus melihat kembali riwayat kesehatan pasien tersebut pada rekam medik. Keberadaan gambaran ateroma pada arteri karotis seringkali ditemukan pada pasien dengan faktor resiko penyakit sistemik seperti penyakit kardiovaskular, riwayat stroke, hipertensi, diabetes melitus, hiperkolesterolemia, perokok, konsumsi alkohol, dan obesitas. Oleh karena aterosklerosis merupakan penyakit yang berhubungan erat dengan beberapa penyakit sistemik yang dapat menyebabkan stroke, maka deteksi dini dari keberadaan ateroma pada arteri karotis ini menjadi suatu hal yang perlu

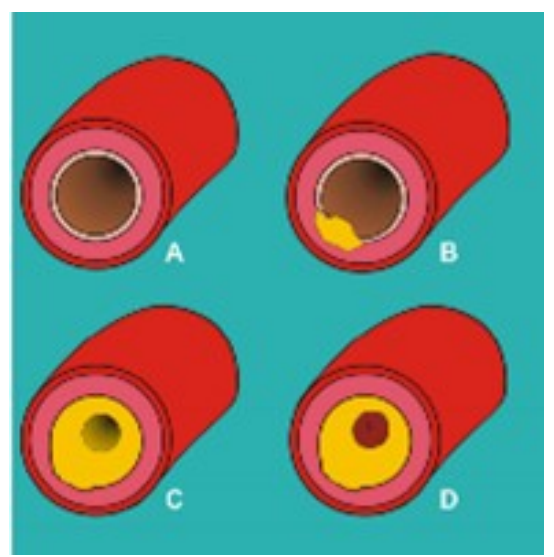

Gambar 1. Diagram sederhana perkembangan aterosklerosis yang menunjukkan: (A) potongan cross-sectional arteri utuh; (B) cedera awal endothelium; (C) formasi ateroma; (D) thrombus yang berhubungan dengan plak dan mengobstruksi secara penuh jalur pembuluh darah 

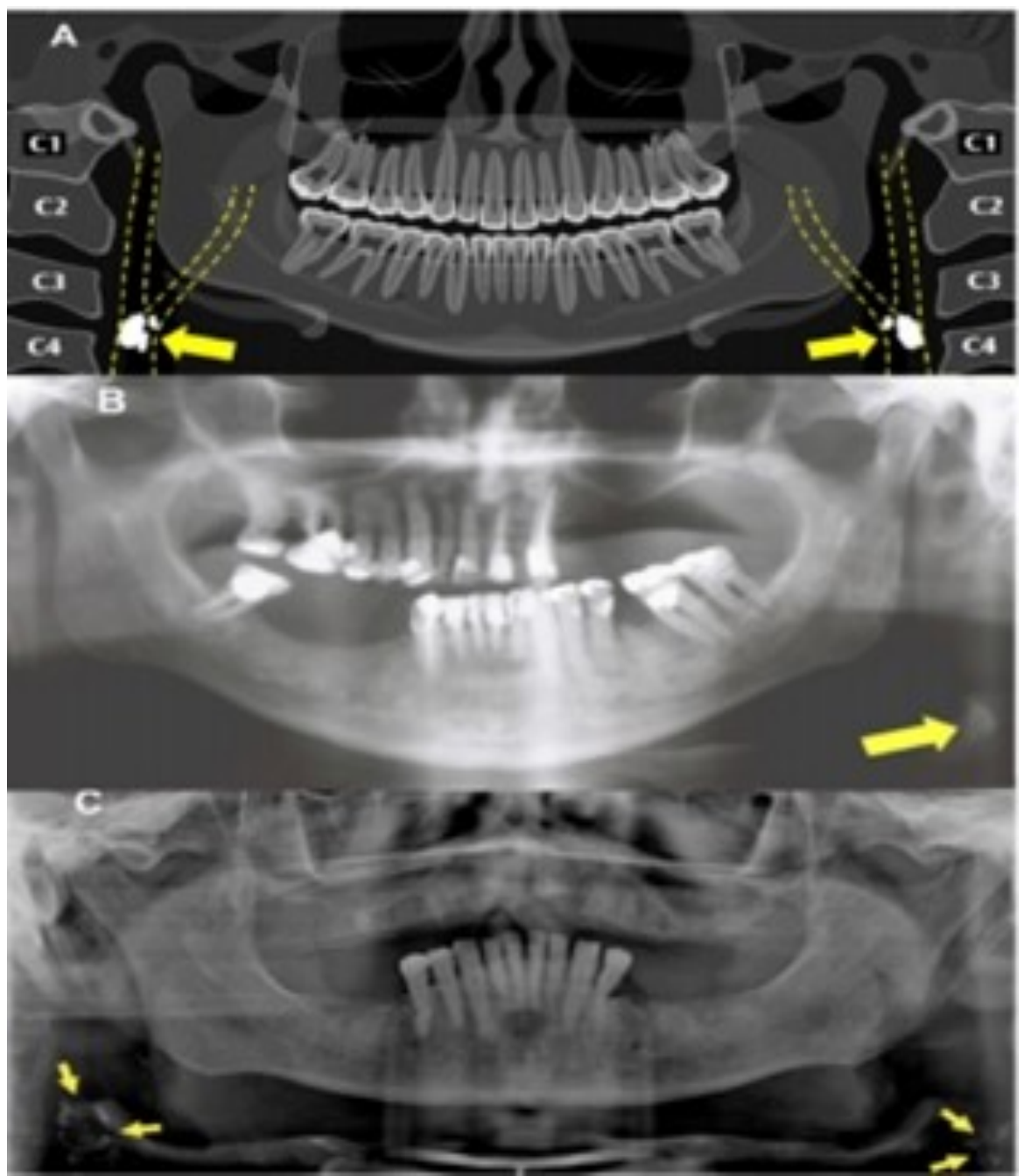

Gambar 2. (A) Ilustrasi radiografi panoramik dengan tanda panah yang menunjukkan ateroma arteri karotid; (B) Radiografi panoramik seorang pasien dengan ateroma pada sisi kiri; (C) Radiografi panoramik pasien dengan bilateral

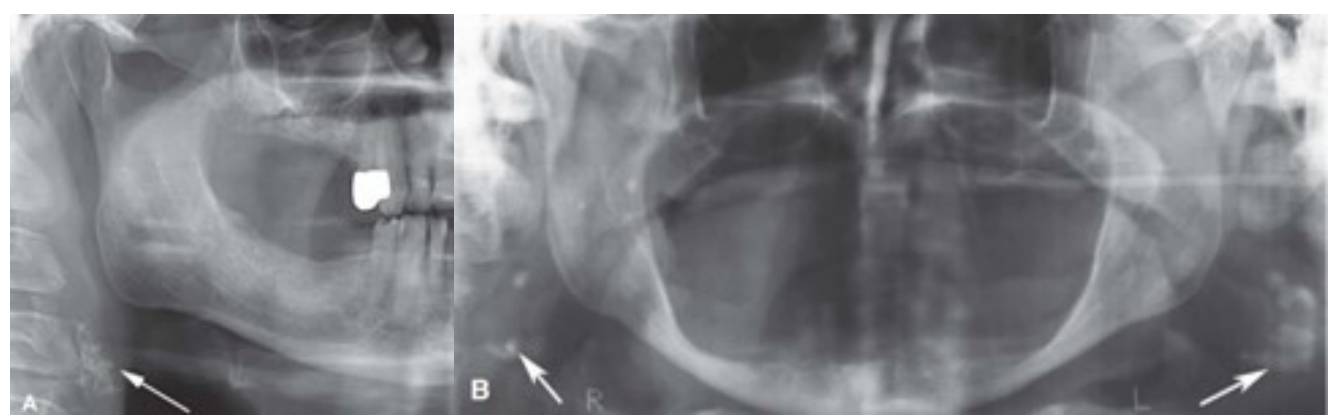

Gambar 3. (A) Potongan radiograf panoramik memperlihatkan kalsifikasi pada arteri karotis;

(B) Radiograf panoramik dengan ateroma arteri karotis bilateral

mendapatkan perhatian dokter gigi. Melalui deteksi dini tersebut, dokter gigi dapat merujuk ke tenaga medis yang lebih berkompeten untuk menangani sehingga kondisi akibat aterosklerosis yang lebih berat dapat dihindari.

Mendeteksi gambaran suatu ateroma pada arteri karotis membutuhkan akuisis dan gigi-gigi pasien berada dalam kondisi beroklusi dan pengalaman yang tinggi dari seorang dokter gigi. bidang Frankfurt Horizontal sejajar lantai. ${ }^{6}$ Hasil Jika dokter gigi belum sepenuhnya yakin akan foto pada teknik ini akan memungkinkan visualisasi radiopasitas yang tampak di sekitar aspek latero- ateroma yang lebih mengarah ke lateral vertebrae, inferior panoramik radiograf, maka sebaiknya merujuk pasien untuk melakukan pemeriksaan radiografi yang lain agar dapat dijadikan sebagai pembanding. Untuk membedakan antara ateroma dan kartilago triticeal, dapat digunakan radiografi dua dimensi lain yaitu proyeksi antero-posterior dengan teknik Modifikasi Towne. Pada teknik ini, 


\section{ANATOMI NORMAL}

Kartilago triticeal

Prosesus styloid

Tulang hyoid

Ligamen stylomandibular

Epiglotis

Tuberkel anterior

\section{LOKASI}

Di antara tulang hyoid dan kartilago thyroid, berbentuk sirkuler atau ovoid di atas vertebrae $\mathrm{C4}$

Di antara ramus mandibula dan dan prosesus mastoid

Di daerah cervical vertebrae, di antara sternum dan basis mandibula

Di atas angulus mandibula, mengalami perluasan dari prosesus styloid hingga ke angulus mandibula

Di kartilago median, tampak bilateral, di bawah tulang hyoid

Di atlas cervical vertebrae pertama

KONDISI PATOLOGIS LOKASI DAN TAMPAKAN RADIOGRAFI

Kalsifikasi nodus limfe

Paling sering di sekitar submandibular hingga ke anterior ramus, dengan kontur irreguler dan internal aspek yang heterogen

Sialolith

Di sekitar glandula submandibular, dengan tampakan irreguler atau radiopasitas yang difus

Tonsilolith

Sering tampak superimposisi dengan ramus mandibula, bisa berbentuk bulat ataupun irreguler

Phlebolith

Pada vena atau pembuluh sinusoid, dengan bentuk sirkuler atau oval

sedangkan kartilago triticeal tidak akan terlihat karena superimposisi dengan spinal.

\section{SIMPULAN}

Keberadaan ateroma pada arteri karotis yang seringkali didapatkan secara insidentil, memungkinkan dokter gigi untuk mendeteksi aterosklerosis secara dini. Dokter gigi harus memahami betul struktur anatomi dan kondisi patologis di sekitar cervical vertebrae yang dapat memberikan tampakan radiopasitas yang mirip dengan ateroma pada arteri karotis. Hal ini penting untuk menghindari kesalahan dalam menginterpretasi ateroma.

\section{DAFTAR PUSTAKA}

1. Aziz M. Pathogenesis of Atherosclerosis A Review Pathophysiology. Med Clin Rev. 2016;2(3):1-6.

2. Mota R, Homeister JW, Willis MS, Bahnson EM. Atherosclerosis: Pathogenesis, Genetics and Experimental Models. eLS. 2017;(November):1-10.

3. Gonçalves JR da SN, Yamada JLY, Berrocal C, Westphalen FH, Franco A, Fernandes Â. Prevalencija patoloških nalaza na panoramskim radiogramima: Kalcificirani aterom karotidne arterije. Acta Stomatol Croat. 2016;50(3):230-4.

4. Brasileiro Junior VL, Luna AHB, Sales MAO de, Rodrigues TLC, Sarmento PL da FA, Mello Junior CF de. Reliability of digital panoramic radiography in the diagnosis of carotid artery calcifications. Radiol Bras. 2014;47(1):28-32.

5. Alves N, Deana NF, Garay I. Detection of common carotid artery calcifications on panoramic radiographs: Prevalence and reliability. Int J Clin Exp Med. 2014;7(8):1931-9.

6. Sung EC, Friedlander AH, Kobashigawa JA. The prevalence of calcified carotid atheromas on the panoramic radiographs of patients with dilated cardiomyopathy. Oral Surg Oral Med Oral Pathol Oral Radiol Endod. 2004;97(3):404-7.

7. Ertas ET, Sisman Y. Detection of incidental carotid artery calcifications during dental examinations: Panoramic radiography as an important aid in dentistry. Oral Surgery, Oral Med Oral Pathol Oral Radiol Endodontology. 2011;112(4):e117.

8. Schroder AGD, de Araujo CM, Guariza-Filho O, Flores-Mir C, de Luca Canto G, Porporatti AL. Diagnostic accuracy of panoramic radiography in the detection of calcified carotid artery atheroma: a meta-analysis. Clin Oral Investig. 2019;

9. Monteiro IA, Ibrahim C, Albuquerque R, Donaldson N, Salazar $F$, Monteiro L. Assessment of carotid calcifications on digital panoramic radiographs: Retrospective analysis and review of the literature. J Stomatol Oral Maxillofac Surg. 2018;119 (2):102-6.

10. Borba DL, Hipólito UV, Pereira YCL. Early diagnosis of atherosclerosis with panoramic radiographs: a review. J Vasc Bras. 2016;15(4):302-7.

11. Tofangchiha $M$, Foroozia $M$, Bakhshi $M$, Bashizade $H$. The carotid artery calcification in type II diabetic patients on panoramic radiographs: An important marker for vascular risk. Sci Res Essays. 2011;6(31):6548-53.

12. Lee JS, Kim OS, Chung HJ, Kim YJ, Kweon SS, Lee YH, et al. The correlation of carotid artery calcification on panoramic radiographs and determination of carotid artery atherosclerosis with ultrasonography. Oral Surg Oral Med Oral Pathol Oral Radiol. 2014;118(6):739-45.

13. Kats L, Vered M, Zlotogorski-Hurvitz A, Harpaz I. Atherosclerotic carotid plaque on panoramic radiographs: neural network detection. Int J Comput Dent. 2019;22(2):1639.

14. Usha VA, David MP. Prevalence of Carotid Artery Atheromas in Postmenopausal Women: A Digital Panoramic Radiographic Study. Jiaomr. 2013;25(June):93-8.

15. White SC, Pharoah MJ. Oral radiology-E-Book: Principles and interpretation. Elsevier Health Sciences; 2014.

16. Vengalath J, Puttabuddi J, Rajkumar B, Shivakumar G. Prevalence of soft tissue calcifications on digital panoramic radiographs: A retrospective study. J Indian Acad Oral Med Radiol. 2014;26(4):385. 